Doi: 10.22478/ufpb.1983-1579.2019v12n3.46674 http://periodicos.ufpb.br/ojs2/index.php

\title{
CONTRIBUIÇÕES DOS FUNDAMENTOS TEÓRICO-METODOLÓGICOS NA ATUAÇÃO DOCENTE DOS PROFESSORES EGRESSOS DO SUBPROJETO PIBID-ARTES VISUAIS DA UEPG/PR
}

CONTRIBUTIONS ON THEORETICAL- METHODOLOGICAL BACKGROUNDS ON TEACHERS TRAINING ACTIVITIS ON SUBPROJECT IPTS - VISUAL ARTS OF PONTA GROSSA STATE UNIVERSITY (UEPG/PR)

Ana Luiza Ruschel Nunes ${ }^{1}$

\begin{abstract}
Resumo: $O$ presente artigo é um recorte de pesquisa pós-doutoral e objetiva apresentar as contribuições dos fundamentos teórico-metodológicos da formação inicial, na atuação docente de egressos do Programa Institucional de Bolsa de Iniciação à Docência (PIBID)/Subprojeto PIBID-Artes Visuais da Universidade Estadual de Ponta Grossa (UEPG/PR), realizado de 2009 a 2014. O PIBID é considerado uma política pública complementar de promoção e valorização da formação docente. Entende-se que a política pública é indicador de ações dos Poderes Públicos no contexto da Política Pública Nacional de Formação de Professores, que é parte de um projeto educacional do Estado Brasileiro. O estudo visa realizar uma reflexão sobre a pós-formação inicial e os processos formativos colaborativos na perspectiva da investigação-ação (CARR; KEMMIS, 1988), da pedagogia histórico-crítica de Saviani $(2008)$ e a pedagogia libertadora de Freire $(1987,1997,2010)$ e sobre os impactos e contribuições da formação e atuação na práxis dos egressos do PIBID-Artes Visuais, na escola. Como resultado, entende que as contribuições são positivas e significativas no percurso profissional dos egressos.
\end{abstract}

Palavras-chave: Política educacional/PIBID. Formação de professores. Artes Visuais, Fundamentos na atuação. Impacto e inovação.
Abstract: This paper is a postdoctoral research and aims at presenting contributions regarding theoretical-methodological backgrounds of the initial training, in graduated teaching performance of the Institutional Program of Teaching Scholarship (IPTS) / Subproject IPTS - Visual Arts of Ponta Grossa State University (UEPG/PR), held from 2009 to 2014. IPTS is considered a complementary public policy that promotes and enhances teacher's training. This public policy is considered an indicator of actions of public authorities based on the context of National Public Policy of Teacher Training, which is part of an educational project of Brazilian State. Thus, this study aims at reflecting on initial post-training and collaborative background processes on research-action perspective (CARR; KEMMIS, 1988), based on Saviani's historical-critical pedagogy (2008) and Freire's liberating pedagogy $(1987,1997,2010)$ and on impacts and contributions of that background and on some performance regarding the graduated praxis from IPTS - Visual Arts, at school. As a result, it is comprised that those contributions are positive and significant along the professional career of graduate students.

Keywords: Educational policy/IPTS. Teacher's training. Visual Arts. Backgrounds on performance. Impact and innovation.

\section{INTRODUÇÃO}

O texto apresenta um recorte de uma pesquisa mais ampla desenvolvida durante estágio pós-doutoral, realizado no Programa de Pós-Graduação em Artes-PPGAV/CEART/UDESC/SC, quando investigamos as Políticas Públicas e o conceito de Estado e os programas historicamente instituídos sobre a formação dos professores de Artes Visuais e as demais iniciativas de implementação de programas que são históricos e, desses o atual Programa Institucional de Iniciação à Docência (PIBID).

\footnotetext{
1 Doutora em Educação pela Universidade Estadual de Campinas. Professora do Departamento de Artes e do Programa de Pós Graduação em Educação da Universidade Estadual de Ponta Grossa/PR. E-mail: analuizaruschel@gmail.com. ORCID: http://orcid.org/0000-0001-7338-1615.
} 
O objetivo deste artigo é compreender o PIBID-Artes Visuais da Universidade Estadual de Ponta Grossa/PR (UEPG/PR), no âmbito da Política Nacional de Formação de Professores, investigando a atuação dos professores de Artes Visuais como profissionais na escola, egressos do PIBID-Artes Visuais/UEPG/PR, para conhecer as contribuições dos fundamentos teórico-metodológicos da formação inicial, na atuação dos professores de Artes Visuais, na docência da educação básica.

O interesse pelo tema se deu no contexto de atuação, quando atuava (2009-2014) como coordenadora do sub-projeto-PIBID Artes-Visuais/UEPG/PR, cujas ações tinham como fundamento o campo epistemológico da teoria dialética crítica marxiana. Dessa experiência surgiu a pergunta: o que os egressos do PIBID fazem com o conhecimento e prática, que se apropriaram no Subprojeto PIBID-Artes Visuais? Essa foi a motivação para a pesquisa, e como formadora de professores me propus a pesquisar objetivando "compreender quais as contribuições dos fundamentos teórico-metodológicos da formação inicial, na atuação docente escolar de egressos do PIBID/Subprojeto Pibid-Artes Visuais da UEPG/PR, de 2009 a 2014".

Acreditamos que as contribuições e os impactos da formação inicial PIBID-Artes Visuais acontecem na docência dos professores na educação básica. Outra questão se põe a indagar se o PIBID-Artes Visuais/UEPG com suas ações propostas contribui com o aprofundamento da teoria e prática pela apropriação dos conhecimentos artístico-científicos e didáticos dos profissionais, ex-participantes do PIBID. O programa em ação há 11 anos é política pública implementada inicialmente com pelo Decreto n. 6.755, de 29 de janeiro de 2009, que institui a Política Nacional de Formação de Profissionais do Magistério da Educação Básica, e disciplina a atuação da Coordenação de Aperfeiçoamento de Pessoal de Nível Superior (Capes) no fomento a programas de formação inicial e continuada, é complementar à Política Nacional de Formação de Professores, que visa à valorização do magistério.

\section{METODOLOGIA}

O recorte que apresentamos se limita a abordar as narrativas dos professores egressos do PIBID do Subprojeto Área de Artes Visuais, do Curso de Graduação em Artes Visuais - Licenciatura, da UEPG/PR atuantes em escola pública e/ou privada como professor efetivo, buscando compreender em que aspectos os fundamentos teórico-metodológicos evidenciam o compromisso de um subprojeto social, ético e estético em sua função educacional que visa contribuir para a formação, emancipação e autonomia de pessoas em diversos grupos interculturais na sociedade, em que a arte e seu ensino têm compromisso social, artístico e estético no desenvolvimento cognitivo e sensível da expressão e criação, na formação humana e humanizadora dos homens e mulheres da sociedade, considerando o Estado Democrático de Direto com mais justiça social.

Dos 18 bolsistas no período de 2009 a 2014, encontramos nove atuando em escolas e outros em instituições que não têm vínculo com o campo da educação e ensino da Artes Visuais, isso se justifica pela ausência de concurso para o magistério. Aqui não computamos as narrativas dos nove efetivos na escola, limitamo-nos a sete pelo limite do artigo. Por uma questão ética seus nomes foram substituídos por PEPAV (Professor Egresso do PIBID/Artes Visuais).

A abordagem da pesquisa é qualitativa teórico-bibliográfica com análise documental, e questionários enviados por e-mail, com 100\% de retorno e ainda diálogos informais presenciais com alguns egressos do Subprojeto/Artes Visuais. Também documentos, como o subprojeto, relatórios, planejamentos de aulas, registro das observações e a teoria que balizou as ações do subprojeto foram considerados.

\section{O PIBID NO CONTEXTO DA POLÍTICA NACIONAL DE FORMAÇÃO DE PROFESSORES}

O Ministério da Educação (MEC) e a Capes, Diretoria de Educação Básica (DEB) vêm aprimorando muitas ações e metas em relação a traçar políticas, ainda que apresentem contradições econômicas, sociais, artísticas e culturais, pois não contempla toda demanda do território educacional. 
É deveras significativo destacar a Política Educacional na valorização do magistério objetivando a qualidade da formação e atuação na educação básica escolar. Por contradição, no contexto atual nacional da formação de profissionais para o magistério, precariza-se a profissionalização e o mundo do trabalho dos professores.

Nesse contexto, o PIBIB, no que diz respeito a questões curriculares - em especial na práxis pedagógica (teoria e prática) nos cursos de licenciatura nas universidades e nas escolas de educação básica - expressa a necessidade constatada de Políticas Públicas na formação e qualificação para a melhoria do magistério e a formação para a docência.

No Relatório do PIBID (2011-2014), os, relatores problematizam e revelam a necessidade de algumas questões sobre currículo nos cursos de licenciatura que exigiram a proposição de um Programa, na implantação do PIBID, destacando, nesse caso, certas questões-problema que foram e estão ainda sendo pensadas, em especial, sobre estrutura curricular para a formação de professores e de como os

Problemas têm sido colocados quanto à estrutura e dinâmica dos currículos dos cursos de formação de professores nas graduações no ensino superior, especialmente no que se refere às relações teoria-prática, formação acadêmica - trabalho na escola. (FUNDAÇÃO CARLOS CHAGAS, 2014, p. 10).

Sendo assim, dispõem sobre o PIBID e o instituí a Portaria Normativa $\mathrm{n}^{\circ} 38$, de 12 de dezembro de 2007. E com base legal o PIBID é inserido na Lei de Diretrizes e Bases da Educação (LDB), Lei n 9.394, de 1996, instituído oficialmente o PIBID como política pública pelo Decreto $n^{\circ} 7.219$, de 2010, que institucionaliza a bolsa de iniciação à docência e, pela Lei $n^{\circ} 12.796$, de 4 de abril de 2013 , que estabelece as Diretrizes e base da educação nacional para dispor sobre a formação dos profissionais da educação, objetivando uma organicidade para pensar e agir com as Políticas Públicas na perspectiva da melhoria da educação básica.

Destarte, é um programa que surge para incentivar e valorizar o magistério e aprimorar a profissão docente por meio da incorporação de bolsas de iniciação à docência para estudantes das licenciaturas bem como para professores da educação básica participantes dos projetos e professores das Instituições de Ensino Superior (IES) para, no conjunto desses três grupos, criar planejamento e formas de atuação com a aprendizagem da docência. Há ainda o quadro de professores gestores que são coordenadores institucionais que administram pedagógica e financeiramente as ações promovidas pelo projeto institucional, em cada IES. Há também a coordenação geral no MEC/Capes/DEB, que faz a mediação entre os projetos institucionais e subprojetos considerando a proposição geral institucional dos princípios e objetivos que regem o PIBID.

No entanto, o Programa vem sofrendo cortes no orçamento, pela crise econômica atingindo a área da educação e por decorrência afeta a Política Nacional de Formação de Professores. O corte orçamentário já prejudicou a viabilização de grande parte do Plano Nacional de Educação (PNE) (2014-2024) e acima de tudo atinge a viabilidade das novas diretrizes para a formação de professores.

Dourado (2016) aponta os desafios para a formação de professores nas IES em relação à formação dos profissionais para o magistério da educação básica. Revela esse autor, que mais de 2 milhões e 100 mil professores, e desses $24 \%$ na educação básica não têm formação em nível superior. Isso é inadmissível e exige do Estado vontade política para constituir e instituir uma política organizacional de forma orgânica em direção à melhoria da formação dos professores numa construção compartilhada em articulação entre as instituições educativas - as instituições da educação básica e educação superior - destacando a construção coletiva e democrática dos projetos pedagógicos entre ambas instituições, o que prevê o PIBID/Capes/DEB. 
Dito isso, reiteramos que a política de formação de professores no Brasil na atualidade, segundo Volsi, Moreira e Godoy (2009) se constitui em representações históricas, com significações que expressam aspectos ideológicos produzida no contexto de mundialização da economia, na fase de vigência da acumulação financeira, flexível e do neoliberalismo numa lógica racional para atender ao capital financeiro.

Para melhor compreensão do PIBID, apresentamos os objetivos propostos pelo Programa, de acordo com a Portaria $n^{\circ}$ 96, de 18 de julho de 2013

a) incentivar a formação de docentes em nível superior para a educação básica; b) contribuir para a valorização do magistério; c) elevar a qualidade da formação inicial de professores nos cursos de licenciatura, promovendo a integração da Educação Superior e a educação básica; d) inserir os licenciando no cotidiano em escolas da rede pública de educação, proporcionando-lhes oportunidades de criação e participação em experiências metodológicas, tecnológicas e práticas docente de caráter inovador e interdisciplinar que busquem a superação de problemas identificados no processo de ensino-aprendizagem; e) incentivar escolas públicas de educação básica, mobilizando seus professores como co-formadores dos futuros docentes e tornando-as protagonistas nos processos de formação inicial para o magistério; f) contribuir para a articulação entre teoria e prática necessária à formação dos docentes, elevando a qualidade das ações acadêmicas nos cursos de licenciatura; contribuir para que os estudantes de licenciatura se insiram na cultura escolar do magistério, por meio da aprovação e da reflexão sobre instrumentos, saberes e peculiaridades do trabalho docente. (BRASIL, 2013).

Transcorridos 11 anos do lançamento do primeiro edital de chamada de projetos PIBID pelo MEC/Capes/FNDE, constatamos um número crescente de publicações abordando aspectos das ações desenvolvidas nos subprojetos e seus impactos para a educação.

Nessa direção, a demanda ampliada é atingida no segundo edital, lançado em 2009, para outras esferas institucionais e níveis de ensino bem como para outras licenciaturas específicas de áreas do conhecimento e para instituições públicas de ensino superior estaduais, caso da UEPG. Os objetivos constantes no primeiro edital não diferem do segundo e são claros quanto às contribuições do Programa para a formação inicial do futuro professor. Para a área de Artes Visuais, o PIBID surge mais precisamente em 2008 nas IES federais e, com mais ênfase, em 2009, quando expande, abrangendo para as universidades estaduais em todo o Brasil. Nesse contexto, origina-se o PIBID na UEPG/PR, em 2009. Em abril de 2013, O PIBID deu um salto qualitativo no reconhecimento de que, por meio de um projeto de lei, foi incorporado no texto da LDB e passou a ser considerado uma política pública oficial, pela Lei 12.796/2013 sancionada pela Presidente da República Dilma Rousseff, alterando a Lei $\mathrm{n}^{\circ}$ 9.394/1996.

O Programa Institucional de Bolsas de Iniciação à Docência (PIBID) traduz de forma inequívoca os princípios e o compromisso da Capes com a formação de professores. Iniciando, em 2009, com 3.088 bolsistas e 43 instituições federais de ensino superior; em 2014, o PIBID alcançou 90.254 bolsistas, distribuídos em 855 campi de 284 instituições formadoras públicas e privadas (em 29 delas há também programas para as áreas da educação escolar indígena e do campo). (BRASIL, 2014, p. 5).

Já em 2014, os organizadores do Relatório PIBID, apresentaram a ampliação histórica dos dados quantitativos, que complementam os dados aqui expostos, dando visibilidade quantitativa desde 2007 até 2014, em que afirmam,

Direcionado inicialmente às Instituições Federais de Ensino Superior e atendendo cerca de 3.000 bolsistas em 2007, das áreas de Física, Química, 
Biologia e Matemática para o Ensino Médio, o Pibid expandiu-se rapidamente, incluindo Universidades Públicas Estaduais, Municipais e Comunitárias, abrangendo todas as licenciaturas. Em 2012 chegou-se a 40.092 Licenciando Bolsistas, 3052 Coordenadores de Área e 6177 Professores Supervisores, num total de 49.321 bolsas, e tem continuado seu crescimento. Em 2014 envolve em torno de 90.000 bolsistas entre todos os participantes, abrangendo perto de cinco mil escolas de educação básica, com a participação de 284 instituições. (FUNDAÇÃO CARLOS CHAGAS, 2014, p. 10).

Nesse contexto, como não aparece no relatório do PIBID, de 2014, dados pontuais da área de Artes Visuais, Dança, Música e Teatro, buscamos dados também no e-Mec para demonstrar o crescimento e a demanda da formação de professores no PIBID, em suas especificidades, como podemos visualizar, na tabela a seguir.

Tabela 1 - Quantitativo das áreas específicas em subprojetos, número de bolsas de iniciação à docência, de supervisores e coordenadores de áreas das Artes Visuais, Dança, Música, Teatro/Artes Cênicas e IES, de 2009 a 2014

\begin{tabular}{|c|c|c|c|c|c|}
\hline $\begin{array}{l}\text { Licenciaturas } \\
\text { específicas de } \\
\text { Artes }\end{array}$ & Suprojetos & $\begin{array}{l}\text { N. de Bolsas } \\
\text { Iniciação à } \\
\text { Docência }\end{array}$ & $\begin{array}{c}\text { N. de } \\
\text { Bolsistas } \\
\text { Supervisore } \\
\text { S }\end{array}$ & $\begin{array}{c}\text { N. de } \\
\text { Bolsistas } \\
\text { Coordenadores } \\
\text { de Área } \\
\end{array}$ & IES \\
\hline $\begin{array}{c}\text { Artes Visuais e } \\
\text { Plásticas e } \\
\text { interdisciplinar } \\
\text { em Artes } \\
\text { Plásticas e } \\
\text { Visuais }\end{array}$ & 57 & 1296 & 132 & 70 & 49 \\
\hline Dança & 22 & 104 & 48 & 28 & 23 \\
\hline Música & 36 & 732 & 78 & 51 & 36 \\
\hline $\begin{array}{c}\text { Teatro/Artes } \\
\text { Cênicas }\end{array}$ & 25 & 546 & 53 & 24 & 28 \\
\hline Total & 140 & 3287 & 981 & 311 & 136 \\
\hline
\end{tabular}

Fonte: Elaborado pela autora a partir de e-Mec (2013, 2014) e Capes (2014)

Esses são dados do PIBIB nacional, atingindo uma demanda de formação inicial e continuada no contexto da Política Nacional de Formação de Professores, e nesse caso a formação para a docência em Artes Visuais, Dança, Música e Teatro/Artes Cênicas. Por ser uma política pública é preciso o acesso abranger todas instituições brasileiras em parceria e convênio, para atender os princípios e objetivos do que se propõem o programa para romper com os desafios da formação como um todo e não apenas a uma parcela das instituições profissionais envolvidos.

Assim, a carência de professores em Artes Visuais, Dança, Música e Teatro percebemos que decorre de fatores sociais e políticos, entre outros, além da falta de investimentos na educação e do próprio status social em que se encontra a profissão docente. Segundo Freitas (2007, p. 2), “[...] as condições perversas que historicamente vêm degradando e desvalorizando a educação e a profissão docente se mantêm em nosso país, em níveis bastante elevados". Para essa autora, em uma política global de formação e valorização da profissão, com a qual concordamos, deveria considerar o tripé "formação inicial, formação continuada e condições de trabalho, salário e carreira", o que não vem se materializando pelas atuais políticas educacionais e pelo atual governo brasileiro, em especial na formação em Artes Visuais, Dança, Música e Teatro/Artes Cênicas. Ressalta-se ainda muito presente a contradição entre a formação específica em Artes Visuais, Dança, Música e Teatro/Artes Cênicas por um 
lado e por outro, na escola, a atuação gerada pela disciplina Artes, ou seja uma atuação polivalente. Romper com essa dicotomia ainda é um desafio.

Daí a necessidade de análise da ação do Estado na criação e implementação dessas Políticas Públicas e nesse sentido a crítica construtiva ao programa de incentivo à docência, que pode contribuir tanto com perspectivas transformadoras, como estacionar na reprodução das mazelas a que assistimos no campo da educação (MOURA, 2013).

Ao fazer uma retomada histórica sobre a formação de professores e o ensino de Artes Visuais no Brasil, Barbosa (2010), Ferraz e Fusari (1993), Fonseca da Silva (2005, 2017), Pimentel (2007), Nunes (2004, 2013, 2014) e outros autores atentam de forma implícita e explícita para a complexidade e ambiguidade dos fatores que influenciam o ensino de Artes Visuais no Brasil. Destacam, dentre tantos, um aspecto muito significativo no campo da formação de professores que parece ser bastante pontual e indiscutível: o ensino de Artes Visuais requer conhecimento técnico, político e profissional. Entretanto, a formação no que tange à autonomia, à emancipação e à formação política do professor ainda está fora do alcance direto do professor, com exceções. Essas questões pontuadas, segundo os autores, exigem uma formação política e crítica para autonomia e liberdade de cátedra ao profissional da educação, visando à formação humana emancipada e cidadã. Para isso, é preciso que o professor tenha formação política e participe de reflexões coletivas na construção de Políticas Públicas na educação e na política cultural e artística considerando o Estado Democrático de Direito.

Para isso, as orientações curriculares em parte estão em consonância com a realidade efetiva da formação inicial de Artes Visuais articulada com a escola, em todas as suas determinações e realidades artísticas e culturais, o que consideramos um dos maiores desafios para a formação do profissional para atuar na educação básica. Para tal questão, corrobora Pimenta (1997) dizendo que é na formação inicial que a construção da identidade do professor começa a se estruturar. Sendo assim, devem ser oferecidas e disponibilizadas oportunidades para que os futuros professores se apropriem de conhecimentos, habilidades e valores necessários à profissão, possibilitando-lhes (re)construir permanentemente seus saberes-fazeres docentes a partir das necessidades e desafios de sua prática pedagógica, aliando a competência técnica e a competência política do profissional da educação e Artes Visuais, com inclusão social e intercultural no ensino das Artes Visuais para uma formação humana e social para todos.

Assim, na perspectiva de Tardif (2014), o saber docente é um saber múltiplo, oriundo da formação profissional, que é o conjunto de saberes a ser ensinado pelas instituições de formação de professores; os saberes disciplinares, que correspondem ao diverso campo do conhecimento e emergem da tradição cultural e intercultural do saber acumulado pela humanidade; saberes curriculares, materializados em programas escolares e universitários e os saberes experienciais oriundos do trabalho cotidiano realizado, em contexto. Todos esses saberes necessários articulados com a formação política e democrática e que exigem do professor estudo para dominar e integrar tais saberes enquanto condição da práxis do cotidiano profissional da prática social e histórico-dialético-crítica. Uma formação que provoca a mediação entre o concreto real-concreto-abstrato-concreto pensando uma mediação que assumimos numa perspectiva teórico pedagógica-metodológica histórico-crítica de Saviani (2008), da Teoria Libertadora de Freire, $(1987,1997,2010)$ e da Teoria Triangular de Barbosa $(1991,2010)$ que contextualiza a arte historicamente e traz a leitura de imagem como princípio e fundamento no ensino e o processo de criação e expressão poética, aliado à análise crítica da arte de forma contextualizada. Esses fundamentos da arte e fundamentos pedagógicos crítico-dialéticos viabilizados na formação inicial para a docência em Artes Visuais fundamentou a formação para a compreensão crítica da educação e em especial das Artes Visuais visando a processos formativos mais justos e humanizados com inclusão social intercultural mais humana, ética e estética para todos.

\section{AS CONTRIBUIÇÕES DOS FUNDAMENTOS TEÓRICO-METODOLÓGICOS NA ATUAÇÃO DOCENTE DOS PROFESSORES DA ESCOLA EGRESSOS DO PIBID}


Fica explícito no decreto que institui o PIBID os seguintes objetivos, no artigo $3^{\circ}$, melhoria da qualidade da educação básica pública, formação de profissionais do magistério e a valorização do docente. Nesse contexto, e para alcançar o propósito maior o PIBID, que, segundo a Capes (2014),

[...] é uma iniciativa para o aperfeiçoamento e a valorização da formação de professores para a educação básica, consolida-se a iniciação à docência para os acadêmicos de licenciaturas de instituições em que por edital foi abrangendo educação superior federais, estaduais, municipais e comunitárias sem fins lucrativos para qualificar a formação dos professores objetivando melhorar a qualidade da educação básica.

Um dos seis subprojetos da UEPG/PR é o PIBID-Artes Visuais (2009-2014) intitulado: "Processos colaborativos na formação do professor e pesquisador em ensino de Artes Visuais: problematização e prática pedagógica emancipatória crítica". Foi com esse subprojeto e seus fundamentos que a formação inicial e continuada do PIBID-Artes Visuais realizou suas ações e metas coerente com teoria pedagógica histórico-crítica e a teoria pedagógica libertadora, como duas possibilidades críticas para a atuação futura profissional no magistério da educação básica. Nesse sentido, o objetivo foi compreender quais as contribuições dos fundamentos teórico-metodológicos da formação na atuação docente na escola, dos professores de Artes Visuais, egressos do PIBID- Artes Visuais/UEPG/PR.

Nessa direção, iniciamos com a narrativa de um dos professores egressos do PIBID-Artes Visuais, que assim se expressa:

“A contribuição que o subprojeto PIBID/Artes Visuais proporcionou na minha prática docente é o pensamento crítico e reflexivo, além da valorização e do encantamento pela profissão docente [...] A teoria pedagógica de Paulo Freire foi muito significativa porque na prática conseguiu-se um ensino de arte pela perspectiva freireana. Os ciclos reflexivos de Carr e Kemmis muito estudados em seu livro de 1988, uma teoria histórico-crítica dialética fazem parte de minha caminhada de atuação profissional na escola." (PEPAV 1).

Como se pode verificar esse professor destaca em sua formação a contribuição e o impacto, porque inovou a sua prática docente pelos fundamentos de estudos e pesquisa do Subprojeto-Artes Visuais e diz ser parte na caminhada de sua profissionalização docente e sua atuação crítica e reflexiva. Isso é importante destacar porque toda a formação foi na perspectiva crítica de ensino de Artes Visuais. O professor ainda destaca a grande contribuição da valorização e do encantamento pela profissão professor docente. Isso é bastante positivo porque muitos alunos entram no curso para ser artistas e isso tangencia contradições com o perfil do aluno que o curso de Artes Visuais quer formar e que no PIBID assumimos, o perfil da docência, formando o professor-artista-pesquisador, objetivando qualificar a formação para o magistério. Diz esse professor que a pedagogia libertadora de Paulo Freire foi uma contribuição fundamental, uma questão significativa, a de ter de fato realizado uma prática pedagógica freireana dialógica e problematizadora de ensino em Artes Visuais. Demarca a formação do professor pesquisador e suas narrativas expressam a contribuição da Espiral Cíclica de Carr e Kemmis (1988), no processo de intervenção pela investigação-ação como fundamento e intervenção pedagógica-metodológica na prática de ensino de Artes Visuais, na iniciação a docência e diz que atualmente está contribuindo e impactando a sua atuação como professor de Artes na educação básica.

Não tão distante das contribuições do exposto, uma PEPAV 2 faz referência importante realçando a teoria e a experiência do PIBID como base para a sua atuação docente quando diz:

“A teoria e a experiência no PIBID me propiciou uma base para atuar como docente depois de formada dando mais segurança para entrar e atuar em sala de aula, o PIBID ajudou durante a graduação principalmente nas regências quando realizei o meu estágio e na preparação de planejamento de aula. 
Propiciou a experiência com alunos de diversas idades e modalidades, o modo de agir perante as situações cotidianas dentro da sala e da escola. A participação no projeto PIBID enriqueceu ainda mais a formação docente e a postura e valores éticos com conhecimentos teóricos e práticos formando a todos nós professoras e professores pesquisadores. Muita produção pedagógica e científica em artes e muita prática artística em poéticas na escola, realizando a transposição didática na formação artística- pedagógica na minha atuação com meus alunos com a Espiral Cíclica de investigação ação". (PEPAV 2).

Pode-se perceber que houve apropriação e contribuição dos saberes e práticas artísticas e pedagógicas e que fica evidente que estão balizando a atuação docente como contribuição do Subprojeto PIBID-Artes Visuais, quando faz referência sobre a segurança que a formação proporcionou, o que consideramos significativo. Quanto a assumir sua autonomia, entretanto, ressaltávamos sempre no Grupo de Trabalho no PIBID que deveríamos como professores relativizar essa segurança e sermos eternos aprendizes, em especial nos conhecimentos, pois não são acabados, mecânicos e fechados. Nesse sentido, corrobora novamente destacando a pedagogia freireana, quando os planejamentos eram construídos no grupo colaborativo e os planos eram já problematizadores. A partir dos três momentos pedagógicos de Delizoikov e Angotti (1990), como contribuição para a sua atuação docente, diz a PPVEV 2: "A participação no projeto PIBID enriqueceu ainda mais a formação docente e a postura e conhecimentos teóricos e práticos formando a todos nós professoras e professores pesquisadores." Essa fala é muito significativa no que se refere aos fundamentos teórico-metodológicos críticos, porque ficou a questão de ensinar e pesquisar na formação quando diz: "Muita produção científica em artes e muita prática artística da poética, na formação artística-pedagógica.” (PEPAV 2).

De fato, essa questão é muito importante, pois buscamos no PIBID-Artes Visuais aprofundar o estudo sobre e da poética aliando os processos criativos de construção de arte moderna e contemporânea na teoria e concepção de poética, que foi na formação inicial uma dificuldade de compreensão dos futuros professores e aliamos ao que referendamos sobre o processo de criação e a interfaces e conexões entre a "poiésis" (produção artística) e a "logo" (discurso), pois a produção artística e a leitura de imagem dessa produção, seja na bidimensão ou tridimensão ou na imagem do cotidiano vivido socialmente no mundo da cultura e das multiculturas e dos objetos sociais e culturais, exigem uma leitura estética e, portanto, sensível e reflexiva de sua própria produção e criação artística. Foi um aprendizado para os acadêmicos, e a processualidade criativa exige conhecimentos desde a intuição/percepção até a engendração do processo criativo de produção, trabalho criador poético com narrativas visuais e análise contextual. Mas o discurso na narrativa visual, da reflexão estética, aliam-se pela poiésis ao criar e produzir com liberdade de expressão e autonomia e ter o direito de não ser indissociável do discurso verbal (logo). Assim, a dialogicidade, como método, segundo Freire, faz a mediação na reflexão estética pessoal e posterior coletiva do grupo na análise e apreciação estética da arte. Quando, já num terceiro momento, ao experienciar a leitura de imagem e praticar a cultura - aqui a cultura e intercultura na crítica da obra de arte em seu contexto e ou do objeto arte e das narrativas do conteúdo expresso em seu plano de expressão visual que já não pertence apenas a quem criou e sim já fazendo parte da cultura artística da escola e da sociedade (PANOFSKY, 1991).

Nesses momentos de apreciação, ocorria uma aprendizagem do que é curadoria e mediação estava posta como conteúdo e, muitas produções artísticas na escola e universidade foi uma articulação muito forte que nos levou a criar uma Galeria de Arte, no corredor da escola, com suportes e material adaptado aos limites e condições da escola; nessa Galeria nunca mais faltaram exposições de arte, tantos dos bolsistas PIBID, como da supervisora e coordenadora PIBID, como em especial trabalhos artísticos permanentemente em exposição pelos alunos da escola. Tudo mediado com conhecimento e práticas artísticas com reflexão estética com todos os envolvidos. Assim a produção científica estava sempre presente, na ação-reflexão-ação e, portanto, embasada teoricamente a partir da práxis da iniciação à docência. 
As narrativas de professores da escola, egressos do PIBID-Artes Visuais (PEPAV 1 e PEPAV 2), destacam que houve apropriação dos fundamentos teóricos na atuação, uma contribuição teórico-prática na aprendizagem de ensinar e a aprendizagem de pesquisar, resultando na produção artística e científica e com grande número de artigos científicos publicados e apresentados em eventos bem como com produção artística apresentadas em exposições e mostras de arte na escola, na universidade e comunidade.

Outros professores destacaram que a investigação-ação está contribuindo no processo de sua atuação docente e diz PEPAV 3 que "Cada vez que vou planejar minha aula, não tem como não relacionar com o aprendizado no PIBID e contribuí na minha atuação docente na escola, ainda as vezes com algumas adequações".

Quanto à concepção de Artes Visuais assim expressam,

"As Artes Visuais contam as histórias e costumes dos povos através das expressões do ser humano, anunciando e denunciando o contexto social dos determinados períodos históricos, nos fazendo compreender um pouco da evolução do mundo em que vivemos, e pensar e refletir sobre ele e as ações do ser humano numa concepção ética e estética para si e para o universal, melhorando nossa percepção em relação a tudo o que nos rodeia." (PEPAV 2).

"Para mim as Artes Visuais se caracterizam pelo conhecimento e produção daquilo que é visual [...] Através das Artes Visuais nos tornamos mais empáticos e consequentemente a docência passa a ser uma causa humanitária humanizadora." (PEPAV 1).

“Artes Visuais é a multiplicidade de formas hibridas e efêmeras. É criação, expressão, fruição e poética [...] As Artes Visuais são expressões da cultura e é um fenômeno social e cultural e estético de cada tempo histórico, mas ela se apresenta em vários âmbitos culturais eruditos, populares e da tradição da arte e na atualidade expande pela arte tecnológica com uma arte hibrida na contemporaneidade." (PEPAV 7).

A concepção de Artes Visuais foi muito estudada e referenciada com obras e objetos da cultura e visualidades na diversidade e diferença, considerando a arte contemporânea sem deixar a arte desde as origens históricas e o modo de produção em cada contexto histórico (NUNES, 2004). A compreensão da concepção de arte com tais narrativas dos professores da escola ex-pibidianos de Artes Visuais, pois nos estudos na universidade muitas tensões e discussões ocorreram porque havia a compreensão de que "arte é sentimento" "arte é técnica de pintura, desenho" concepções do senso comum com base numa razão instrumental. Assim foi preciso discutir esse tema pela necessidade de um saber específico colocando a arte primeiro numa dimensão e concepção singular (a realidade objetiva, o cotidiano vivido), segundo Lukács (2011), e numa dimensão universal (o conhecimento científico e artístico - a ser ensinado) e para tal segundo Lukács $\left(1968^{\mathrm{a}}\right)$ necessita da categoria da particularidade entendida como mediação entre o singular e o universal. Daí a teoria estética para refletir e compreender o pensar do outro, e em especial na formação de professores para aprendizagem. Se não tivermos os saberes da arte e seu processo criativo ou o que Lukács (2011) se refere na teoria do reflexo em seus três pilares: a teoria do reflexo cotidiano, reflexo científico e reflexão estética, passagem que tem o ponto de partida no vivido e percebido (singular) e posterior para o concebido (quando da aprendizagem dos conceitos científicos e artísticos). Assim a arte em sua visão universal perpassa pela compreensão do singular vivido para chegar ao científico e artístico correlato com conceitos e saberes/conhecimentos constituídos historicamente e nesse processo, de forma consciente e intencional a teoria da reflexão estética (LUKÁCS, 2011) na convergência e proximidade cada vez maior para dirimir a distância do singular e universal na arte visual permite a reflexão estética das Artes Visuais tendo como objeto de sua arte o humano. É fundante a mediação pela categoria da particularidade na abordagem de Lukács 
(1968a) para pensar criticamente a Arte e ensiná-la, ainda que o objeto da expressão na arte não seja o homem em seu sentido artístico, é o homem o objeto da arte numa estética reflexiva crítica. Lukács (1968a) daí a abordagem dele ter como princípio estético a principal categoria - a particularidade - o particular como mediação (purificação) entre o singular e o universal. Para ele o papel da particularidade na estética é o ato de refletir a realidade objetiva, mediação via reflexão. Entretanto destacou nesse contexto de que o problema da categoria da particularidade era um dos mais negligenciados, tanto do ponto de vista lógico como do ponto de vista estético.

Assim temos aí concepções críticas da arte como conhecimento, cultura e a arte visual como uma prática social da humanidade. Fundamentos necessários na formação inicial na perspectiva histórico-dialético-crítico, coerente com e na perspectiva histórico-crítica. Percebemos que a concepção da arte como técnica pela técnica, e da arte como apenas sentimento foi superado durante os estudos do PIBID, pois as falas dos egressos denotam a compreensão crítica. Destaca-se também a questão de que a arte é desigual e depende do contexto cultural em que é produzida; diz um professor egresso

“[...] que a discussão da divisão da produção artística e do modo de produção capitalista numa sociedade dividida em classes sociais é forte e muito presente na escola, concebe que há contradições em vários âmbitos culturais - eruditos e populares -, trabalhei em duas escolas, uma com alunos de classe média alta e outra de classe pobre e isso fez com que tivesse que inovar e se não fosse o PIBID estudar sobre diferentes realidades culturais e interculturais e de classe social, não saberia como resolver a minha atuação docente e pedagógica" (PEPAV 6).

É uma formação que denota competência técnica e política. Compreender o sistema capitalista e as diferenças socioculturais é necessário para saber lidar os diferentes modos de produção da arte; corroboram Vásquez (1978) e Nunes (2004) para a abordagem da arte e trabalho criador.

Em outra questão indagamos aos professores egressos, quais foram os fundamentos pedagógico-metodológicos da formação, e qual pressuposto teórico-pedagógico que embasa sua atuação docente:

"O Subprojeto PIBID-Artes Visuais/UEPG/2009 era fundamentado na teoria crítica da educação e da arte, e foi proporcionado duas teorias: o fundamento teórico pedagógico de Paulo Freire e o fundamento pedagógico de Saviani. Também na pesquisa colaborativa e na pesquisa-ação participativa emancipatória critica de investigação-ação em Carr e Kemmis." (PEPAV 1).

"Teoria crítica da arte e a teoria de Carr e Kemmis de investigação-ação emancipatória crítica busco na investigação-ação pela Espiral Cíclica realizar o planejamento - ação - observação - realizar uma reflexão posterior para um (re)planejamento. Inicio investigando o que o aluno já sabe e ver o que ele não sabe, para planejar a ação como docente por meio da prática educativa, aliando sempre prática-teoria-prática, observar o processo de aprendizagem e ver o que ele aprendeu e se for necessário replanejar, aprendi que essa espiral é flexível, " (PEPAV 3).

"Teoria Crítica da Educação e da arte, sempre problematizando os saberes da arte de forma contextualizada e crítica como conhecimento e expressão humana." (PEPAV 4).

Em continuidade, ao narrar os caminhos e processos na prática da iniciação à docência em Artes Visuais do PIBID, o professor expressa que

"A perspectiva da pesquisa colaborativa de investigação-ação emancipatória crítica permitiu um caminho de processos de ensino colaborativos com certa 
autonomia profissional ampliando tanto os saberes para a docência-como saber curricular, saber pedagógico, saber das nossas experiências na formação, saberes da arte da tradição, saberes das artes e da história da arte, dos processos de criação artística, da tecnologia, da cultura visual, da cultura popular, da estética do cotidiano e da arte e trabalho, na sociedade. A prática dos saberes das Artes Visuais erudita e das diferentes culturas em sua diversidade. Considero que a contribuição da pesquisa colaborativa através da investigação-ação emancipatória, proporcionada pelo subprojeto PIBID/Artes Visuais, modificou minha visão sobre a docência e colaborou para com a minha formação docente, tanto no aspecto pessoal e humano quanto no profissional em colaboração pois isso na minha atuação é uma continuidade." (PEPAV 1).

Sobre a prática educativa de formação, na universidade e na escola durante atuação no PIBID e qual impacto dessas aprendizagens para a formação colaborativa e individual, diz o professor de Artes Visuais, egresso do PIBID-Artes Visuais,

"Na universidade durante a graduação tínhamos bastante teoria estudávamos os métodos e procedimentos metodológicos a serem utilizados em sala de aula, mas tínhamos pouco tempo para ficar em sala de aula e percebi depois ao realizar o estágio que o curso não nos dá grandes experiências para atuarmos como docentes. No PIBID apesar de também termos teoria, tínhamos muita prática em sala de aula e eram 20 horas semanais tanto nas experiências de planejamento e execução, na observação de aulas quanto na atuação com regências na organização do trabalho educativo e com a teoria e prática ali pudemos experienciar o que dava certo e o que não dava certo em sala de aula, para posterior refletir e redimensionar replanejando para novas ações tanto no ensino como na pesquisa a professora da escola de artes visuais foi também muito importante para a gente saber o como se faria para ensinar um conteúdo contando a realidade da escola, ela planejava junto no grupo. Importante que a gente aprendia o conhecimento da arte e já organizava a transposição didática tendo a formação pedagógica junto." (PEPAV 2).

Ainda outro egresso e professor de escola atualmente, assim disse:

"Muitas contribuições dos fundamentos proporcionaram e aprendi muito desde as aulas planejadas sob os fundamentos da pedagogia histórico-crítica seguindo os procedimentos e percurso [...] Os alunos com essas aulas e a metodologia ficam mais críticos. Eu registro os conteúdos e a frequência de alunos." (PEPAV 3 )

Ainda diz o professor egresso:

"Uma outra questão importante foi que a professora coordenadora e supervisora de área Artes Visuais que orientavam o PIBID tirou xerox para cada um de nós do caderno de frequência da escola e junto com a supervisora explicaram o uso e registros no caderno de frequência. [...] Foi muito significativo, e essa necessidade teve impacto - me sentia professora quando assumi as aula na escola. Ter conhecimento, saber planejar as aulas, ter metodologia para ensinar, fazer uma ação compartilhada com outra área de forma interdisciplinar e preciso contar que na minha atuação como professora hoje na escola tem a grande contribuição teórica do PIBID e como tudo tornou-se na prática agora na escola como professora, é sensacional, pois tenho mais segurança em sala e me sinto preparada para dar aulas, dialogar com gestor, saber do PPP. Agora sou professora !!!” (PEPAV 2). 
Ao solicitar aos sujeitos, egressos do PIBID-Artes Visuais para que analisasse criticamente de forma aberta os processos de estudo e pesquisas e se isso ocorre como professor de Artes Visuais como profissional da escola, eles dizem que,

\begin{abstract}
“Hoje, com as necessidades da sala de aula vejo o quanto o PIBID é um programa primordial para uma formação mais aprofundada na licenciatura. As experiências que teoricamente tivemos em sala de aula durante as intervenções nos mostraram novas perspectivas e possibilidades de atuar em sala de aula. Perceber que o currículo não é algo fixo, mas que ele precisa ser maleável e que é necessário e possível, planejar e replanejar de acordo com as necessidades da sala de aula, foi uma das coisas que mais colaborou com a minha prática hoje na escola. Pois é preciso levar em consideração aspectos sociais dos indivíduos de maneira crítica" (PEPAV 3 ).
\end{abstract}

"Estudamos as teorias críticas de educação para optarmos com conhecimento qual fundamentar a nossa prática futura. Estudamos muito duas a teoria pedagogia freiriana e a pedagogia histórico-critica de Saviani. Também retomamos a teoria da arte e os fundamentos da linguagem visual, história da arte mundial, latianomericana e a historia da arte popular e interculturalidade, estudamos Cultura, multicultura, estudamos gestão (decretada e gestão construída), o Projeto Político Pedagógico do colégio e o regimento, as Diretrizes Curriculares do Estado do Paraná para o Ensino de Arte, Estudamos Planejamento. E estudamos o planejamento Anual da professora regente de Artes Visuais na escola (então supervisora PIBID-Artes Visuais), planejamos as aulas com base em nossos estudos teóricos-pedagógicos. Estudamos tipos de pesquisa. e sempre com discussões na universidade e as vezes na escola. Observamos as aulas de forma participativa da professora de Artes Visuais. Sempre estávamos respaldados pela espiral reflexiva de Carr e Kemmis e da pesquisa colaborativa com base também em Ibiapina (2010), para que a investigação e a reflexão da própria prática fossem uma realidade transformadora. Fizemos pesquisas e publicamos artigos em eventos do PIBID e também da área, além de publicação de um livro que registra um momento impar do nosso grupo de trabalho colaborativo e tenho um artigo." (PEPAV 1).

Considerando o perfil que se quer formar, indagamos aos ex-bolsistas se eles consideram ser um professor-artista e pesquisador, como egresso do PIBID e do Curso de Artes Visuais? E se depois do PIBID já havia produzido um artigo e ou obra de arte.

"Com certeza me considero, pois sou um crítico de mim mesmo e considero que ainda estou em formação, então a pesquisa desempenha uma importante ferramenta formativa e que instiga as relações interpessoais, quando compartilhamos nossas pesquisas estamos ampliando o campo das discussões e consequentemente contribuindo para com a melhoria da educação. $E$, nesta caminhada continuo pesquisando, portanto me considero um professor pesquisador." (PEPAV 1).

Ainda diz sobre a produção científica e artística,

"Quando retornei à escola como professor tinha como um dos objetivos observar e coletar informações para possíveis pesquisas e publicações. Infelizmente por causa da dinâmica de ter que trabalhar em três colégios, fui levado a exaustão e aquilo que pretendia ainda está no plano das ideias. Pretendo, elaborar um artigo relatando a experiência vivenciada neste ano de 2016." (PEPAV 1). 
Nesse sentido, a precarização do trabalho profissional do professor é muito grande, Como disse Moura (2013) é preciso pensar na qualificação, mas também sua profissionalidade como salário e tempo para sua autoformação, pois três turnos de trabalhos na educação básica é desqualificar a profissão, o trabalho e formação dos alunos, na escola. Outra professora assim expressa:

"[...] O projeto de pesquisa é de grande importância para os acadêmicos bolsistas, pois visa uma melhora na formação, trazendo uma base teórica e prática na realidade escolar, de como é atuar como professor em sala de aula, nos dando um suporte para depois de formados assumirmos as turmas com mais segurança, como está acontecendo comigo na escola. (PEPAV 2).

[...] a produção depois que saí do PIBID não produzi mais artigos relacionados à pratica educativa dou aula em três escolas, não tenho tempo mais, gostaria, não consegui mais produzir minhas poéticas e isso é triste!" (PEPAV 2).

O impacto da formação inicial para a docência em Artes Visuais o que marca de forma muito forte para você? Diz uma egressa:

“A Espiral Reflexiva de Carr e Kemmis (1988), também a teoria pedagógica de Paulo Freire, a consciência de que estamos em formação contínua e a importância de se produzir pesquisas e de compartilhá-las com outros pesquisadores e de ter melhorado muito minha prática educativa em Artes Visuais." (PEPAV 1).

O planejamento foi uma polêmica, pois diziam que o professores na escola não planejava sua aula como no PIBID, então nos desafiamos e juntos a professora supervisora da escola, a coordenadora de área de Artes Visuais, e outro professor da universidade fizemos a discussão e nos propomos a juntos construir o planejamento. Assim buscamos com a teoria freireana e a teoria histórico-crítica organizar na ação docente o planejamento para as aulas. Assim ao indagar se eles realizam o planejamento, a execução e avaliação, diz o professor:

"Sim, eu planejo minhas aulas [...] ao planejar as aulas utilizo o roteiro de planejamento para as aulas de Artes Visuais, elencando o eixo temático a partir do conhecimento e o conteúdo, organizando-o com os três momentos pedagógicos estudados: a) Estudo da realidade artística, cultural em contexto da prática social dos alunos (os saberes prévios dos alunos em relação ao conteúdo e as vivencias ou não em relação ao saberes artísticos e científicos; b) Problematização inicial sobre e do conteúdo a ser ensinado/aprendido da Arte Visual (em que problematizo sobre e do conteúdo a ser ensinado fazendo questionamentos ao coletivo da turma em sala de aula e das falas subjetivas dos alunos e suas realidade vividas em relação ao conhecimento do conteúdo da arte elenco o tema gerador; c) Organização do conhecimento e neste caso sistematizo o conteúdo planejado e o processo de ensino entra em ação docente com mediação e diálogo para que o aluno aprende e aqui a leitura da obra de arte, bem como imagens da cultura visual mais ampla é abordada e sem dúvida não dissocio do contexto local e histórico da arte mundial situando como disse nossa professora coordenadora do PIBID da necessidade do enfoque historiográfico como necessário a objetivação dos saberes acumulados ao longo da história da humanidade e portanto como um saber a ser ensinado e pertinente a formação humana histórica e crítica; d) e por último do uso social do conhecimento é o terceiro momento - a aplicação do conhecimento aprendido pelo alunos e então oportuniza-se com possibilidades de transpor estes conhecimento da arte visual para a situação problema da realidade em contexto e de reorientar a busca para soluções possíveis a partir 
de uma compreensão da realidade agora não mais espontânea e percebida mas numa compreensão mais elevada do saber aprendido e portanto voltando a realidade desse saber artístico e cultural agora pensado, (uma dialética que aprendi no PIBID), agora compreendido de forma crítica e no movimento histórico da História da Arte conscientemente compreendida, foi muito bom esse PIBID na minha formação." (PEPAV 1).

Essa narrativa dá a conhecer o quanto o PIBID e os processos formativos colaborativos e compartilhados tornam a ação compartilhada não mais solitária do professor na escola com a teoria e a prática articuladas. Assim, complementa a PEPAV 2, assinalando que: "[...] às vezes planejo as aulas como fazia no Subprojeto Artes Visuais." e ainda diz com preocupação: "[...] é nas vezes que utilizo do planejamento dos três momentos pedagógicos os alunos aprendem melhor.", e revela: "[...] trabalho em três turnos e em escolas diferentes, e portanto não tenho condições de planejar de forma melhor, por isso não é como no PIBID." (PEPAV 2). Mais uma vez denota nessas narrativas a precarização e o tempo do trabalho docente e o quanto isso precisa ser repensado na profissionalização dos profissionais da educação básica. Diz ainda esse professor: "Trabalho os três turnos por necessidade de viver um pouco melhor".

Ao responder e justificar porque não realizava o planejamento, foi questionado de como organizava suas aulas e quais caminhos metodológicos realiza em sua ação docente e a professora, egressa do PIBID, segue a Espiral Cíclica de Carr e Kemmis (1988) pela sua narrativa:

"Realizo meu planejamento síntese, vou para ação educativa e ao ensinar observo atentamente em processualidade, sistematizando os conteúdos e observando as atitudes e se a apropriação e reflexão do conteúdo esta sendo aprendido pelos alunos e depois da aula realizo sempre uma reflexão apontando tudo para posterior pensar criticamente minha atuação na aula e se consegui atingir os objetivos na aprendizagem do conteúdo crítico pelos alunos, e se caso for necessário replanejo e/ou planejo nova aula e ensino conhecimentos novos." (PEPAV 2).

E ainda completa a professora: "[...] o impacto maior do PIBID-Artes Visuais foi a pesquisa pela investigação-ação emancipatória crítica, que eu e nenhum dos alunos pibidianos naquela momento e nem a professora supervisora conheciam." (PEPAV 2). A pesquisa colaborativa de investigação-ação que é um pressuposto epistemológico de intervenção crítico-emancipatória e ao mesmo tempo uma metodologia e caminho didático para aprender a ensinar e aprender a pesquisar. Diz ainda, "Uso esse processo em espiral de investigação-ação emancipatório que tanto estudei, e realizo na prática do ensino de Artes Visuais na minha escola." (PEPAV 2). Infere-se conforme a narrativa que uma prática pedagógica exige conhecimento. Saberes das Artes Visuais e saberes pedagógicos para a mediação do ensino e aprendizagem das Artes Visuais. Assim indagou-se quê conhecimento/conteúdo ensina o professor egresso do PIBID e que teoria e prática artística ensina na escola em que atua profissionalmente? Disse um professor egresso:

"Com certeza a formação inicial foi fundamental para a minha formação e na atuação docente, e o PIBID deve continuar porque deu um aprofundamento maior teórico - prático, no campo de nossa futura atuação e só tenho a agradecer a aprendizagem para a docência." (PEPAV 1).

Outro egresso do PIBID disse:

"Fui buscar mais conhecimento em livros e artigos para aprimorar os conhecimentos sobre diversos saberes da arte visual, foi e será sempre uma busca frequente por informações, pois como professor preciso de saberes para transpor esse saber a ser ensinado na escola [...] por mais que se estude, aprendi que nunca será o suficiente para sabermos tudo o que deveríamos saber." (PEPAV 2). 
Outra professora relata que muitas vezes faz falta e precisa estudar mais para ensinar. Ela relembrou das ações educativas e o ensino na escola em que atuaram no período do PIBID-Artes Visuais na escola, dizendo:

\begin{abstract}
"Sim, mas lembro que vivenciamos uma situação que é possível exemplificar que nem tudo é suficiente na formação inicial, pois quando no PIBID aconteceu que na escola um conteúdo estava no Programa anual da disciplina de Arte que era a História da Arte Latino-americana. Estava no planejamento da professora de Artes Visuais da escola e foi indicado pela professora de Artes Visuais da escola para que nós alunos déssemos esse conteúdo nas aulas. Para surpresa, o grupo colaborativo se deparou com uma problemática, não sabíamos esse conteúdo. O nosso curso não tem esse conteúdo no currículo. Como fazer? Esse conteúdo não constava no Projeto Pedagógico do Curso de Licenciatura em Artes Visuais/UEPG/PR. Isso foi levado e problematizado no GT-PIBID-Artes Visuais e tivemos que buscar esse conhecimento que nenhum dos alunos e alunas pibidianos(as) sabiam. Assim este conteúdo está na escola como um saber a ser ensinado e não está no currículo e programas no Curso de Artes Visuais. Assim, como aconteceu na universidade e escola com o PIBID, ocorre também agora como professor efetivo no ensino de Artes Visuais na escola e quando não temos suficiente conhecimento mais aprofundado, temos que pesquisar e para isso tivemos também uma formação muito boa como pesquisador e assim temos que pesquisar." (PEPAV 4).
\end{abstract}

Assim para que houvesse uma intervenção no Curso de Artes Visuais, solicitou-se a uma das professoras de História da Arte, se poderia dar uma aula com esse conteúdo para os alunos e então fizemos um seminário na universidade, de modo que se apropriassem desse saber historicamente acumulado e ensinar para os alunos na escola.

Hoje esse conteúdo da História da Arte Latino-americana está incorporado na Matriz Curricular no Projeto novo reformulado em 2015, do Curso de Graduação em Artes Visuais.

$\mathrm{Na}$ formação inicial, existe um discurso de que o que se ensina e aprende na universidade não serve como saberes a ser ensinado para a escola. O que realizamos no Subprojeto PIBID-Artes Visuais, você considera inviável na escola em que atua e se sim, por quê?

"Eu considero viável tudo o que foi ensinado, pois além de melhorar os conhecimentos dos acadêmicos bolsistas preparam para a docência, traz novos ares as escolas trazendo atividades/conhecimentos que geralmente não são ensinados, pois com a correria do dia a dia e o grande número de turmas o professor que atua em sala de sala não consegue trazer muitas atividades diferenciadas. Tudo e o todo do nosso PIBID em Artes Visuais foi de qualidade e até hoje está presente na minha atuação na escola e sala de aula." (PEPAV 3 ).

Outro egresso traz uma questão vivenciada na escola e diz:

[...] quando a nossa coordenadora e orientadora do PIBID-Artes Visuais no que tange à realização das oficinas nos dois turnos aos sábados na escola, envolvia as $6^{\circ}, 7^{\circ}, 8^{\circ}, 9^{\circ}$ anos da escola do PIBID, ela sempre fazia conosco reflexões sobre o tempo de hora/aula que era de 50 minutos de aula ser muito pouco para a práxis pedagógica e produção artística e então em comum acordo, no grupo colaborativo, todos juntos decidimos realizar as oficinas na escola. Mas ao decidir as oficinas, por exemplo, nós bolsistas ao propor oficina de escultura não acreditamos que daria para fazer mesmo sendo na quadra de esportes da educação física (única solução), com o material de concreto celular. A nossa 
coordenadora PIBID-Artes Visuais e orientadora nos desafiou e planejamos e realizamos a oficina em três sábados em sequência e para cada oficina três sábados e para a surpresa da professora da escola e dos bolsistas PIBID, realizamos essa oficina que foi um sucesso. Nunca mais vou duvidar da possibilidade de os alunos realizarem a produção e criação em Artes Visuais como extensão das aulas para práticas artísticas em hora extra-classe. As poéticas foram realizadas e com muita criação e foram expostas na escola para ser apreciadas por toda comunidade escolar e pais dos alunos. Então essa criação/produção que achamos e tínhamos conviç̧ão que não conseguiríamos com os alunos, resultou em uma criação artística que impactou a todos e também a toda escola." (PEPAV 5).

Já um dos professores, egresso do PIBID-Artes Visuais diz ouvir que o que se aprende na universidade depois não aproveitam para a escola e diz: "[...] nada do que foi proposto pelo Subprojeto PIBID-Artes Visuais pode ser considerado inviável para a realização na escola." (PEPAV 4). E o outro professor acrescenta:

"[...] temos que sair da zona de conforto e planejar, pensar na aprendizagem dos alunos tanto da arte e sua história, como da cultura visual mais ampla na comunidade e nos aliar com os demais professores da escola para construir processo colaborativo interdisciplinar e multidisciplinar." (PEPAV 5).

E completa:

[...] tudo é possível, mas confesso uma proposição colaborativa interdisciplinar ou multidisciplinar, precisa uma estruturação de toda a escola e de todo o projeto pedagógico, porque temos praticamente um turno para planejar para mais de 8 turmas em diferentes anos, como fazer isso tudo? Eu acho que é só para dizer que fizemos. Nos professores efetivos temos 40 horas/aula e um turno para planejar." (PEPAV 5).

Concordamos com a professora egressa do PIBID, porque o professor precisa pensar a sua profissionalidade.

Já outra professora diz:

"[...] ainda precisa ver o salário que recebemos e a responsabilidade de ser professor. Temos que ir até tarde da noite planejando, bem como nos sábados e domingo temos que fazer trabalhos em casa, trabalho que deveria ser realizado na escola". (PEPAV 3 ).

Essa é uma concreta precarização do trabalho docente, que precisa ser levado em conta pelos gestores públicos para valorizar a educação e a carreira e sem dúvida precisa ser melhor qualificada. Percebemos as contribuições do PIBID-Artes Visuais e seus fundamentos teórico-metodológicos da formação em sua atuação na docência em Artes Visuais, na escola básica.

\section{CONSIDERAÇÕES FINAIS}

Pode-se inferir, que as contribuições dos fundamentos teórico-metodológicos da formação para a atuação docente dos professores, egressos do PIBID-Artes Visuais demonstram uma apropriação e compreensão dos fundamentos teórico-metodológicos na prática pedagógica para o ensino e a aprendizagem das Artes Visuais.

Nessa direção, tecem-se algumas considerações pontuando que a formação de professores na mediação entre os saberes da arte e saberes pedagógicos viabilizam pela investigação-ação uma prática na totalidade da prática social educativa em Artes Visuais e na cultura e intercultura presente na escola. Portanto, na aprendizagem gerada por uma teoria pedagogia libertadora por alguns egressos PIBID e 
por outros pela teoria pedagógica histórico-crítica são fundamentos que têm sua essência na teoria crítica da educação e ensino. Infere-se que a aprendizagem da docência e seus saberes na universidade e escola bem como dos fundamentos e conceitos científicos, artísticos e estéticos não são, na docência, ponto de chegada de um desenvolvimento precedente e, portanto, independente do ensino, pois isso se caracterizaria como saber prévio. Daí a necessidade de abstração para o pensamento racional apropriar-se da realidade objetiva, pois os conceitos artísticos e estéticos e seus fundamentos, se comparados aos conceitos espontâneos, possuem a possibilidade de muito maior peso pela sua grande capacidade de síntese, de sistematização e de generalização. É preciso uma formação que cria uma ruptura na zona de desenvolvimento real na aprendizagem da docência, geradora de uma compreensão ingênua, e alcançar o desenvolvimento potencial, mediação fundante do professor formador na aproximação de ambos - zona proximal ou emitente a que Vigostski (1999) se refere, para sofrer uma transformação realizada pela atividade humana.

Infere-se as contribuições dos fundamentos teórico-metodológicos da formação e formas de trabalho criador pela técnica, arte, tecnologia, e prática social, que exigem a sistematização artística e estética em seu modo de poiéses (produção) e sua interconexão com o logo (discurso) pelo processo da arte como trabalho criador fundamentado na pedagogia libertadora pela maioria e a opção da pedagogia histórico-crítica por outros na atuação docente, no ensino das Artes Visuais na escola.

A ciência e a arte, sendo conhecimentos, são formas de busca e reflexão do concreto vivido, percebido e concebido, pelos instrumentos e signos necessários ao desenvolvimento da consciência de formas de operacionalidade de trabalho criador da arte (nesta, a arte visual) como expressão e conhecimento objetivado e não de neutralidade, para não recair no positivismo.

Pode-se concluir, o Subprojeto de Artes Visuais traz muitas contribuições necessárias para oportunizar a instrumentação para as alternativas voltadas aos problemas inerentes ao processo de formação e atuação na docência, e ao assumirem a carreira docente e, por decorrência a contribuição visível dos fundamentos teórico-metodológicos da formação inicial e que mobilizem os professores egressos como professor, artista e pesquisador, atuantes na escola. Contribuem para valorizar e ampliar a qualidade da formação inicial de professores de Artes Visuais para a educação básica.

Esperamos, para finalizar, que o empenho político seja a garantia das condições objetivas, de gestão administrativa e o financeiro, para o PIBID como uma politica pública, e que o programa aliado às Diretrizes Curriculares Nacionais de forma recíproca com a Política Nacional de Formação de Professores se concretize na articulação do ensino superior e a educação básica num percurso que consolide de fato e que garante a profissionalização dos professores.

\section{REFERÊNCIAS}

BARBOSA, A. M. A imagem no ensino da arte. São Paulo: Perspectiva; Porto Alegre: fundação lochpe, 1991.

BARBOSA, A. M.; CUNHA, F. P. (org.). A abordagem triangular no ensino das artes e culturas visuais. São Paulo: Cortez, 2010.

BRASIL. Constituição da República Federativa do Brasil. Promulgado em 15 de outubro de 1988. Disponível em: <http://www.planalto.gov.br/ccivil_03/constituicao/ConstituicaoCompilado>. Acesso em: 13 maio 2014.

. Decreto ${ }^{\circ} 7.219$ de 25 de junho de 2010. Dispõe sobre o Programa Institucional de Bolsa de Iniciação a Docência e dá outras providências. Disponível em: <http://www.planalto.gov.br/ccivil_03/_ato2007-2010/2010/Decreto/D7219.htm>. Acesso em: 10 jun. 2013. 
. Portaria Capes $n^{\circ}$ 96, de 18 de julho de 2013. Fica aprovado, na forma dos Anexos I e II, o Regulamento do Programa Institucional de Bolsa de Iniciação à Docência (PIBID). Disponível em: <http://abmes.org.br/legislacoes/detalhe/1434/portaria-capes-n-96>. Acesso em: 4 jul. 2019.

. Portaria Normativa ${ }^{\circ} 38$, de 12/12/2007. Dispõe sobre o Programa Institucional de Bolsa de Iniciação à docência (PIBID). Diário Oficial da União, 2007. Seção 1, n. 239, p. 39.

. Projeto de Lei $n^{\circ} 7.032 / 2010$. Altera os $\S \S 2^{\circ}$ e $6^{\circ}$ do art. 26 da lei $n^{\circ} 9.394$, de 20 de dezembro de 1996, que fixa as diretrizes e bases da educação nacional, para instituir, como conteúdo obrigatório no ensino das Artes, a música, as artes plásticas e as artes cênicas. 2010a Disponível em <http://www.camara.gov.br/sileg/integras/831016.pdf>. Acesso em: 12 de dez. 2016.

BRASIL. Ministério da Educação. Plano Nacional de Educação. Brasília, DF, 2014. Disponível em: <http://pne.mec.gov.br/>. Acesso em: 18 set. 2015.

. Edital $n^{\circ} 01$, Capes, de 3 de janeiro de 2011: convida instituições públicas de Ensino Superior a participarem do PIBID. Brasília, 2011.

. Edital $n^{\circ}$ 02, de 25 de setembro de 2009. Amplia o PIBID à instituições públicas estaduais. Brasília, DF, 2009. Disponível em:

<https://www.capes.gov.br/images/stories/download/bolsas/Editalo2_PIBID2009.pdf>. Acesso em: 4 jul. 2019.

. Portaria $n^{\circ} 260$, de 30 de dezembro de 2010. Aprova as normas do Programa Institucional de Bolsa de Iniciação à Docência (PIBID). Brasília, DF, 2010b. Disponível em:

<https://www.capes.gov.br/images/stories/download/legislacao/Portaria260_PIBID2011_NomasGerais.p df>. Acesso em: 4 jul. 2019.

BRASIL. Ministério da Educação. Lei de Diretrizes e Bases da Educação nº 9.394 de 20 de dezembro de 1996. Estabelece as Diretrizes e Base da Educação Nacional. Brasília, DF, 1996. Disponível em: <htpp://portal.mecd.gov.br/arquivos /pdf/idb.pdf>. Acesso em: 10 abr. 2014.

BRASIL. Ministério da Educação. Conselho Nacional de Educação. Chamada Pública MEC/CAPES/FNDE nº 01/2007. Seleção pública de propostas de projetos de iniciação à docência voltados ao Programa Institucional de Iniciação à Docência (PIBID): primeiro edital do PIBID. Brasília, DF, 2007. Disponível em: <https://capes.gov.br/pt/educacao-basica/capespibid/editais-e-selecoes>. Acesso em: 4 jul. 2019.

. Parecer do CNE/CES n 01/2009, de 16 de janeiro de 2009. Aprova Diretrizes Curriculares Nacionais do curso de Graduação em Artes Visuais e dá outras providências. Disponível em: <http://portal.mec.gov.br/cne/arquivos/pdf/pceb22_05.pdf_. Acesso em: 14 out. 2017.

. Resolução CNE/CP n ${ }^{\circ}$ 02, de $1^{\circ}$ de Julho de 2015. Diretrizes Curriculares Nacionais para a formação de professores inicial em nível superior (cursos de licenciatura, cursos de formação pedagógica para graduados e cursos de segunda licenciatura) e para formação continuada. Disponível em: <http://portal.mec.gov.br/docman/agosto-2017-pdf/70431-res-cne-cp-002-03072015-pdf/file>. Acesso em: 4 jul. 2019.

. Resolução CNE/CES n ${ }^{\circ}$ 01, de 16 de janeiro de 2009. Dispõe sobre as Diretrizes Curriculares Nacionais do Curso de Graduação em Artes Visuais, bacharelado e licenciatura. Disponível em: <http://portal.mec.gov.br/cne/arquivos/pdf/2009/rces001_09.pdf_. Acesso em: 4 jul. 2019.

BRASIL. Ministério da Educação. Instituto Nacional de Pesquisas em Educação. Relatório de Área ENADE 2014: artes visuais. Brasília, DF: INEP, 2014. Disponível em: <download.inep .gov.br/educação .../2014 _rel_artes visuais_licenciatura.pdf>. Acesso em: 12 dez. 2015.

CARR, W.; KEMMIS, S. Teoria crítica de la enseñanza: la investigación del profesorado. Barcelona: Martinez Roca, 1988. 
ISSN 1983-1579

Doi: 10.22478/ufpb.1983-1579.2019v12n3.46674

http://periodicos.ufpb.br/ojsz/index.php

DELIZOICOV, D.; ANGOTTI, J. A. Metodologia do ensino de ciências. São Paulo: Cortez, 1990.

DOURADO, L. F. Formação de profissionais do magistério da educação básica: novas diretrizes e perspectivas. Revista Comunicação \& Educação, São Paulo, ano XX, n.1, jan./jun. 2016

FERRAZ, M. H. C. de T; FUSARI, M. F. de R. Metodologia do ensino de arte/educação. São Paulo: Cortez, 1993.

FREIRE, P. Pedagogia do oprimido: saberes necessários a pratica educativa 17. ed. Rio de Janeiro: Paz e Terra, 1987.

. Pedagogia da autonomia. 4. ed. Rio de Janeiro: Paz e Terra, 1997.

. Educação e emancipação. São Paulo: Paz e Terra, 2010.

FREITAS, D.N.T. de. A avaliação da educação básica no Brasil: dimensão normativa, pedagógica e educativa Dirce Nei Teixeira de Freitas Campinas: Autores Associados, 2007.

FONSECA DA SILVA, M. C. R. A Formação de professores de Arte: diversidade e complexidade pedagógica. Florianópolis: Insular, 2005.

Estágio supervisionado: escolhas didáticas no curso de licenciatura em Artes Visuais. In: Cadernos de Docência: problematizações da teoria/prática no estágio supervisionado. Florianópolis: AAES, 2017.

FUNDAÇÃO CARLOS CHAGAS. Um estudo avaliativo do Programa Institucional de Bolsa de Iniciação à Docência (PIBID). Pesquisadores Bernardete A. Gatti; Marli E. D. A. André; Nelson A. S. Gimenes; Laurizete Ferragut, pesquisadores. São Paulo: FCC/SEP, 2014. Disponível em: <http://www. capes. gov. br/images/stories/download/bolsas/24112014-PIBID-arquivoAnexado.pdf>. Acesso em: 7 nov. 1015.

LUKÁCS, G. Romance Histórico. São Paulo: Editora Boitempo, 2011.

- Introdução a uma Estética Marxista: Sôbre a Particularidade como Categoria da Estética. Tradução de Carlos Nelson Coutinho e Leandro Konder. Rio de Janeiro: Civilização Brasileira, 1968a.

MOURA, E. J. S. Políticas Públicas em Educação: o PIBID e a formação inicial de professores de Artes Visuais. In: ENCONTRO NACIONAL DE PESQUISADORES EM ARTES PLÁSTICAS, 22., Anais... Belém: ANPAP/PPGARTES/ICA/UFPA, 2013.

NUNES, A. L. R. Artes Visuais e processos colaborativos de iniciação à docência e pesquisa. Organizado por Ana Luiza Ruschel Nunes. Ponta Grossa: UEPG, 2013.

. Ensino de Arte na educação básica. In: AMARAL, M. das Vitórias N. do; SILVA, M. B. (org).

Conferências em Arte/Educação: Narrativas Plurais. Recife: Gráfica Flamar Editora, 2014.

. Trabalho, Arte, Educação- formação humana e prática pedagógica. Santa Maria: UFSM, 2004.

PANOFSKY, E. Significado nas artes visuais. Tradução de Maria Clara F. Kneese e J. Fuinsburg. 3. ed. São Paulo: Perspectiva, 1991.

PIMENTA, S. G. A. A didática como mediação na construção da identidade do professor, uma experiência de ensino e pesquisa na licenciatura. In: ANDRÉ, M. E. D.; OLIVEIRA, A. M. R. N. S. (org.). Alternativas do ensino de didática. Campinas. São Paulo: Papirus, 1997.

SAVIANI, D. Pedagogia Histórico- Crítica: primeiras aproximações.10. ed. Campinas: Autores Associados, 2008.

TARDIF, M. Saberes docentes e formação profissional. 16. ed. Petrópolis: Vozes, 2014. 
CONTRIBUIÇÕES DOS FUNDAMENTOS TEÓRICO-METODOLÓGICOSNUNES, A. L. R.

VOLSI, M. E. F; MOREIRA, J. A. S.; GPSOY, G. A. V. Políticas atuais para a formação de professores da educação básica e as novas diretrizes nacionais para a formação docente. Collóeuium Humanarum, Presidente Prudente, v. 14, n. 3, p.123-135, jul./set. 2019.

Recebido em: 30/05/2019

Aceito em: $14 / 08 / 2019$

Publicado em: 03/10/2019 